\title{
PENINGKATAN KEMAMPUAN REPRESENTASI MATEMATIS MELALUI PEMBELAJARAN KONTEKSTUAL SISWA KELAS VIII SMP
}

\author{
Ahmad Rustam ${ }^{1}$, Sardin $^{2}$ \\ ${ }^{1,2}$ Program Studi Pendidikan Matematika, FKIP Universitas Sembilanbelas November Kolaka \\ ahmadrustam@usn.ac.id ${ }^{1}, \underline{\text { sardin@gmail.com }}{ }^{2}$
}

\begin{abstract}
This research is an experimental research with the aim to know: (1) improvement of the average of mathematical representation skills of class VIII student of SMP Negeri 2 Uluiwoi before getting learning with contextual approach; (2) improvement of the average of mathematical representation skills of grade VIII student of SMP Negeri 2 Uluiwoi before getting learning with conventional approach; (3) an average increase in student representation skills taught by a contextual learning approach is better than an increase in the average of mathematical representation skills taught by conventional learning. The population in this study is all students of class VIII SMP Negeri 2 Uluiwoi academic year 2016/2017 spread in 2 parallel classes with the number of 46 people. The population consists of two classes, then the sample is chosen by specifying the first class as the experimental class and the second class as the control class, assuming that the two classes are statistically homogeneous. This data collection technique uses test and observation techniques. Data analysis techniques use descriptive statistics and inferential statistics. The results of empirical research indicate that; (1) Improvement of mathematical representation skills of class VIIIA students taught by using contextual learning model consisting of 24 students showed average value 46,25 and deviation standard 7,409 with mean increase or average $\mathrm{N}$-Gain value 0,42 is in the medium category. The improvement of the mathematical representation skills of VIIIB class students taught by using conventional learning model which consist of 22 students shows the average value 49,09 and deviation standard 15,402 with mean increase or average of $\mathrm{N}$-Gain value equal to 0,25 is at low category. Inferential statistical analysis shows that (1) there is an increase in the average ability of students 'mathematical representation after having contextual learning, (2) There is an increase in the average ability of students' mathematical representation after conventional learning, and (3) students' mathematical representation with the application of contextual approach is higher than the conventional learning model in Grade VIII students of SMP Negeri 2 Uluiwoi.
\end{abstract}

Keywords: Improved, Contextual, Conventional, N-Gain, mathematical representation skills.

\section{PENDAHULUAN}

Bidang ilmu matematika banyak memegang peranan dalam perkembangan ilmu pengetahuan. Oleh karena itu, sebagai langkah awal untuk mengarah pada kemajuan suatu bangsa adalah dengan mendorong atau memberi motivasi belajar matematik bagi siswa.

Matematika memegang peranan penting dalam menunjang keberhasilan penguasaan ilmu pengetahuan dan teknologi. Mengingat peranan yang begitu penting, maka siswa dituntut untuk dapat menguasai materi matematika secara tuntas, akan tetapi saat ini masih rendahnya kemampuan matematika siswa dalam berbagai jenjang pendidikan yang masih jauh dari pencapaian kualitas pendidikan Indonesia.

Berdasarkan laporan hasil The Third Internasional Mathematic and Science Study diketahui bahwa: "Kemampuan siswa sekolah Menengah Pertama di Indonesia dalam mempresentasikan ide atau konsep matematika dalam materi pembagian dan bilangan, aljabar, geometri, representasi data, analisis, dan peluang termasuk rendah". Contoh, ketika siswa Indonesia diminta untuk membuat persamaan dari tabel yang merepresentasikan hubungan antara dua variabel, 
Ahmad Rustam ${ }^{1}$, Sardin $^{2}$ : Peningkatan Kemampuan Representasi Matematis melalui Pembelajaran Kontekstual Siswa Kelas VIII SMP

ternyata kemampuan representasi siswa indonesia adalah $27 \%$, sedangkan kemampuan rata-rata Internasional 45\%” (Mudzakkir, 2006: 6). Dengan keadaan seperti ini perlu metode pengajaran yang optimal dan inovatif, untuk itu menurut Sudjana (1989: 57) bahwa ada beberapa hal yang harus menjadi bahan pertimbangan dalam menentukan metode mengajar yang akan digunakan, yaitu: (a) tujuan pengajaran yang akan dicapai; (b) bahan ajar yang akan diajarkan; (c) jenis kegiatan anak didik yang diinginkan. Sehingga dalam melaksanakan kegiatan proses belajar mengajar, seharusnya seorang guru memahami langkah-langkah yang harus ditempuh. Lie (2008: 4) menyatakan bahwa guru perlu melaksanakan kegiatan pembelajaran berdasarkan pokok-pokok pemikiran sebagai berikut: (1) pengetahuan ditemukan, dibentuk, dan dikembangkan oleh siswa; (2) siswa membangun pengetahuan secara aktif; (3) guru perlu berusaha mengembangkan kompetensi siswa; (4) pendidikan adalah interaksi pribadi di antara siswa dan interaksi antara guru dan siswa, untuk membangun pengertian dan pengetahuan secara bersama-sama.

Menurunnya dan rendahnya tingkat prestasi Indonesia dalam ajang TIMSS disebabkan karena semakin menurunnya tingkat kemampuan representasi, siswa SMP di Indonesia. Hal ini dapat di lihat pada hasil pekerjaan salah satu siswa dalam menyelesaikan soal TIMSS yang menunjukkan rendahnya kemampuan representasi matematis siswa Indonesia.

Beberapa anak sedang bermain sebuah permainan di sebuah lapangan. Mereka membentuk kelompok dengan anggota 2 orang. Tini dan Tina adalah teman satu kelompok. Pada permainan tersebut, mata Tina ditutup dengan sapu tangan, kemudian Tini memandu pergerakan Tina untuk mendapatkan bola yang telah ditentukan tempatnya. Kelompok yang paling cepat mendapatkan bola tersebut adalah pemenangnya. Tini memberikan arahan pada Tina, "Maju 3 langkah, kemudian ke kanan 4 langkah, maju 1 langkah, kemudian maju lagi 1 langkah”. Gambarkalah dalam grafik kartesius langkah yang ditempuh Tina dan tentukanlah posisi Tina mendapatkan bola tersebut.

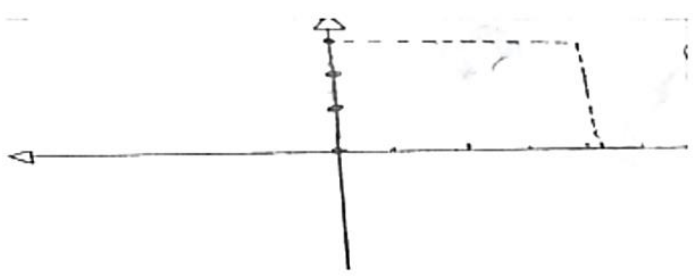

Gambar 1. Salah Satu Jawaban Siswa yang

Menunjukkan Rendahnya Kemampuan Matematis

Siswa

Berdasarkan jawaban siswa terlihat bahwa tidak terpenuhinya salah satu indikator kemampuan representasi yaitu menyajikan kembali data dari suatu cerita ke dalam gambar. Hal ini terlihat dari jawaban siswa yang memperlihatkan bahwa siswa belum mampu merepresentasikan hal-hal yang diketahui dari soal, sehingga siswa tidak mampu menggambarkannya ke dalam garis kartesius dan siswa hanya mampu menggambarkan garis kartesius tanpa mampu memperlihatkan proses tranformasi pada soal, selain itu juga siswa belum mampu menuliskan prosedur dari proses transformasi pada soal kedalam kalimat matematika. Melihat kenyataan ini, kemampuan representasi matematis siswa harus segera dilatih dan ditingkatkan demi tercapainya tujuan pembelajaran matematika sehingga dapat meningkatkan prestasi belajar matematika siswa.

Perlunya pembelajaran yang tepat dalam meningkatkan kemampuan representasi matematika siswa. Hamruni (2011: 132) menyatakan bahwa pembelajaran kontekstual adalah suatu pembelajaran yang menenkankan pada proses keterlibatan siswa untuk dapat menemukan materi yang dipelajari dan menghubungkannya dengan situasi kehidupan nyata, 
sehingga mendorong siswa untuk dapat menerapkannya dalam kehidupan nyata. Selain itu, Johnson (Agung dan Suryani, 2012: 75) menyatakan CTL adalah sebuah proses pendidikan yang menolong peserta didik melihat di dalam materi akademik yang mereka pelajari dengan cara menghubungkan subjek-subjek akademik dengan konteks kehidupan pribadi, sosial, dan budaya. Pembelajaran kontekstual dapat dikatakan sebagai sebuah pendekatan pembelajaran yang menunjukkan kondisi alamiah dalam ilmu pengetahuan. Nurhadi (Kurniasih dan Sani, 2015: 140) menyatakan Pembelajaran Kontekstual adalah konsep pembelajaran yang mendorong guru untuk menghubungkan antara materi yang diajarkan dan situasi dunia nyata siswa.

Penerapan pembelajaran efektif akan berimbas pada meningkatknya kemampuan/siswa misalnya kemampuan representasi, dimana situasi nyata akan di ubah dalam bahasa matematis yang lebih abstrak agar mudah diselesaikan secara matematik. Menurut dalam Mustangin (2015:16) Representasi adalah alat-alat yang digunakan individu untuk mengorganisasikan dan menjadikan situasi-situasi lebih bermakna. Sedangkan, menurut Goldin (Hasana, 2004: 19) Representasi adalah konfigurasi atau bentuk susunan yang dapat menggambarkan, mewakili atau melambangkan sesuatu dalam satu cara.

NCTM (2000: 67) representasi yang dimunculkan oleh siswa merupakan ungkapanungkapan dari gagasan-gagasan atau ide-ide matematika yang ditampilkan siswa dalam upayanya untuk mencari suatu solusi dari masalah yang dihadapinya. Kemampuan representasi matematis siswa dapat di ukur melalui beberapa indikator kemampuan representasi matematis. Menurut Suryana (2012: 41) kemampuan representasi matematis diukur melalui 3 indikator yaitu gambar,
Persamaan atau ekspresi matematis, dan Kata-kata atau tes tertulis.

\section{METODE}

Jenis penelitian Quasi Eksperimental menggunakan rancangan Pretest-Posttest Control Group Design dengan menerapkan dua model pembelajaran yang berbeda pada kelas eksperimen dan kelas kontrol yaitu Pembelajaran dengan pendekatan Kontekstual dan Pembelajaran Konvensional (PKV).

Penelitian ini dilaksanakan di SMPN 2 Uluiwoi kelas VIII tahun ajaran 2015/2016.

Populasi dalam penelitian ini adalah seluruh siswa kelas VIII SMPN 2 Uluiwoi yang terdiri dari 2 kelas yaitu kelas $\mathrm{VIII}_{\mathrm{A}}, \mathrm{VIII}_{\mathrm{B}}$, dengan jumlah 46 siswa yang dideskripsikan pada tabel 1 berikut:

Tabel 1. Rata-rata Nilai hasil Tes kemampuan awal Matematikan Siswa

\begin{tabular}{cc|cc}
\hline No & Kelas & $\begin{array}{c}\text { Banyak } \\
\text { Siswa }\end{array}$ & $\begin{array}{c}\text { Rata-rata nilai } \\
\text { ulangan harian } \\
\text { semester Ganjil }\end{array}$ \\
\hline 1 & VIII $_{\text {A }}$ & 24 & 72,875 \\
2 & VIII $_{\text {B }}$ & 22 & 70,6363 \\
\hline & Total & 46 & \\
\hline
\end{tabular}

Berdasarkan deskripsi dari populasi tersebut, maka penliti menetapkan kedua kelas tersebut sebagai kelas eksperimen dan kelas kontrol dengan beberapa pertimbangan asumsi bahwa kedua kelas tersebut memiliki kemampuan yang homogeny. Berikut hasil pehitungan secara statitik penetapan sampel penelitian pada Tabel 2.

Tabel 2. Hasil Uji Homogenitas Rata-rata Nilai Ulangan Harian Siswa Kelas VII SMP Negeri 2 Kolaka

\begin{tabular}{cc}
\hline Levene Statistic & Sig. \\
\hline 0,007 & 0,933 \\
\hline
\end{tabular}

Tabel tersebut, menunjukkan bahwa hasil uji homogenitas dengan metode Levene's Test dengan $\mathrm{P}_{\text {value }}(\mathrm{sig})=0,933>\alpha=0,05$ maka $\mathrm{H}_{0}$ di terima, 
sehingga disimpulkan bahwa data populasi kelas VII homogen. Dengan asumsi inilah peneliti menetapkan kedua kelas tersebut sebaka kelas penelitian yaitu sebagai kelas eksperimen dan kelas kelas kontrol.

Teknik pengumpulan data melalui teknik tes dan non tes atau observasi. Teknik tes digunakan untuk mengumpulkan data yang berkaitan dengan kemampuan representasi matematika siswa. Observasi menggunakan lembar observasi guru dan siswa yang di dalamnya berupa pernyataan yang sesuai dengan prosedur pembelajaran kontekstual.

Penelitian ini menggunakan instrumen tes kemampuan representasi matematis ini berupa tes uraian yang diberikan pada saat pretest dan postest. Pretes dan postes diberikan pada kelas eksperimen dan kelas kontrol. Pretes diberikan di awal kegiatan penelitian dan hasil pretes akan digunakan untuk mengukur kemampuan awal siswa. Sedangkan postes diberikan di akhir kegiatan penelitian.

Adapun pedoman penskoran kemampuan representasi matematis disajikan pada tabel 3 berikut:

Tabel 3. Pedoman Pemberian Skor Kemampuan Representasi Matematis

\begin{tabular}{|c|c|c|c|}
\hline$\frac{\overrightarrow{0}}{\omega}$ & $\begin{array}{l}\text { Mengilustra } \\
\text { sikan }\end{array}$ & $\begin{array}{l}\text { Menyataka } \\
\text { n/Menggam } \\
\text { barkan }\end{array}$ & $\begin{array}{l}\text { Ekspresi } \\
\text { Matematis }\end{array}$ \\
\hline 0 & \multicolumn{3}{|c|}{$\begin{array}{l}\text { Tidak ada jawaban, kalaupun ada hanya } \\
\text { memperhatikan ketidakpahaman tentang } \\
\text { konsep sehingga informasi yang diberikan } \\
\text { tidak berarti apa-apa. }\end{array}$} \\
\hline 1 & $\begin{array}{l}\text { Hanya } \\
\text { sedikit dari } \\
\text { Penjelasan } \\
\text { yang benar }\end{array}$ & $\begin{array}{l}\text { Hanya } \\
\text { sedikit dari } \\
\text { gambar, } \\
\text { diagram, } \\
\text { namun } \\
\text { kurang } \\
\text { lengkap dan } \\
\text { benar }\end{array}$ & $\begin{array}{l}\text { Hanya sedikit } \\
\text { dari } \\
\text { Model } \\
\text { matematika } \\
\text { yangbenar }\end{array}$ \\
\hline 2 & $\begin{array}{l}\text { Penjelasan } \\
\text { secara } \\
\text { Matematis } \\
\text { masuk akal } \\
\text { namun } \\
\text { hanya } \\
\text { sebagian } \\
\text { lengkap dan }\end{array}$ & $\begin{array}{l}\text { Melukiskan } \\
\text { diagram,sec } \\
\text { ara lengkap } \\
\text { dan benar }\end{array}$ & $\begin{array}{l}\text { Menemukan } \\
\text { model } \\
\text { matematika } \\
\text { dengan benar, } \\
\text { namun salah } \\
\text { dalam } \\
\text { mendapatkan } \\
\text { solusi }\end{array}$ \\
\hline
\end{tabular}

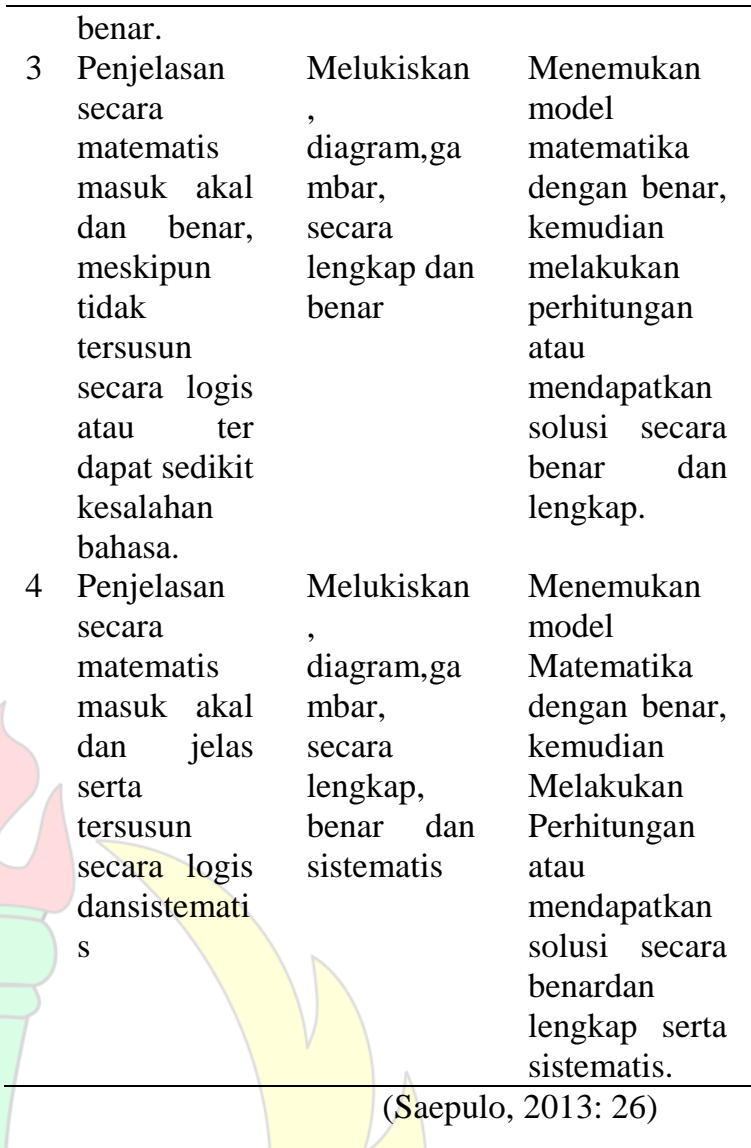

Sebelum tes tersebut digunakan, terlebih dahulu telah diujicobakan dengan maksud mengukur validitas butir soal dan reliabilitasnya. Perhitungan reliabilitas soal dan validitas butir soal digunakan perangkat lunak SPSS. Untuk reliabilitas soal digunakan Cronbach-Alpha (Sundayana, 2014: 69) dan untuk validitas butir soal digunakan korelasi pearsom product moment dari Karl Pearson (Djaali dan Muljono, 2008: 53), yaitu korelasi setiap butir soal dengan skor total. Diperoleh 6 butir soal yang valid dengan nilai reliabilitas sebesar 0,510 dengan kategori sedang, dalam arti bahwa instrument dapat digunakan.

Lembar observasi disusun berdasarkan penerapan pendekatan kontekstual. Lembar observasi ini bertujuan untuk mencatat responrespon yang muncul dari siswa berkaitan dengan situasi masalah yang diberikan guru ketika pembelajaran dengan pendekatan kontekstual.

Data yang dianalisis yaitu data tes kemampuan 
representasi matematis siswa menggunakan analisis statistik deskriptif dan analisis inferensial. Analisis deskriptif digunakan untuk mendeskripsikan data penelitian.

Analisis data menggunakan statistik deskriptif dikelompokkan menjadi tiga bagian yaitu distribusi frekuensi, pemusatan data dan penyebaran data (Rustam, 2016: 27).

Analisis data dengan statistik inferensial digunakan untuk menguji hipotesis, menggunakan dua analisis uji beda beda rata-rata diantaranya uji beda dua rata-rata sampel berpasangan untuk data nilai N-Gain pretest-Posttest dan uji beda dua ratarata sampel bebas untuk nilai $\mathrm{N}$-Gain kelompok eksperimen dan kontrol, dengan asumsi bahwa data yang akan di analisis yaitu homogen dan berdistribusi normal,

Rumus Uji beda rata-rata satu sampel:

$t=\frac{\bar{X}_{i}-\mu_{0}}{\frac{s}{\sqrt{n}}} \quad$ (Rustam, 2016: 80).

$$
\begin{aligned}
t_{\text {hitung }} & =\frac{\bar{X}_{1}-\bar{X}_{2}}{s_{g a b} \sqrt{\frac{1}{n_{1}}+\frac{1}{n_{2}}}} \text { Dengan: } \\
s_{g a b} & =\sqrt{\frac{\left(n_{1}-1\right) s_{1}{ }^{2}+\left(n_{2}-1\right) s_{2}{ }^{2}}{n_{1}+n_{2}-2}}
\end{aligned}
$$

Keterangan:

(Dowdy, dkk, 2004: 192)

$\mathrm{t}$ : t-hitung

$\bar{X}_{i}$ : rata-rata N-Gain kelas (eskperimen atau kontrol)

$\mu_{0}:$ Nilainya " 0 "

$s$ : simpangan baku

$S_{g a b}$ : simpangan baku gabungan

$n_{i}$ : jumlah anggota sampel

\section{HASIL DAN PEMBAHASAN}

Hasil analisis data kemampuan representasi matematis dalam penelitian ini disajikan secara deskriptif maupun hasil analisis statistik inferensial.

a. Hasil Analisis Deskriptif

Hasil analisis deskriptif data hasil kemampuan komunikasi matematis pada kelas eksperimen dan kelas kontrol dapat dilihat pada tabel 4 berikut:

Tabel 4. Deskriptif Data Kemampuan Representasi Matematis Siswa

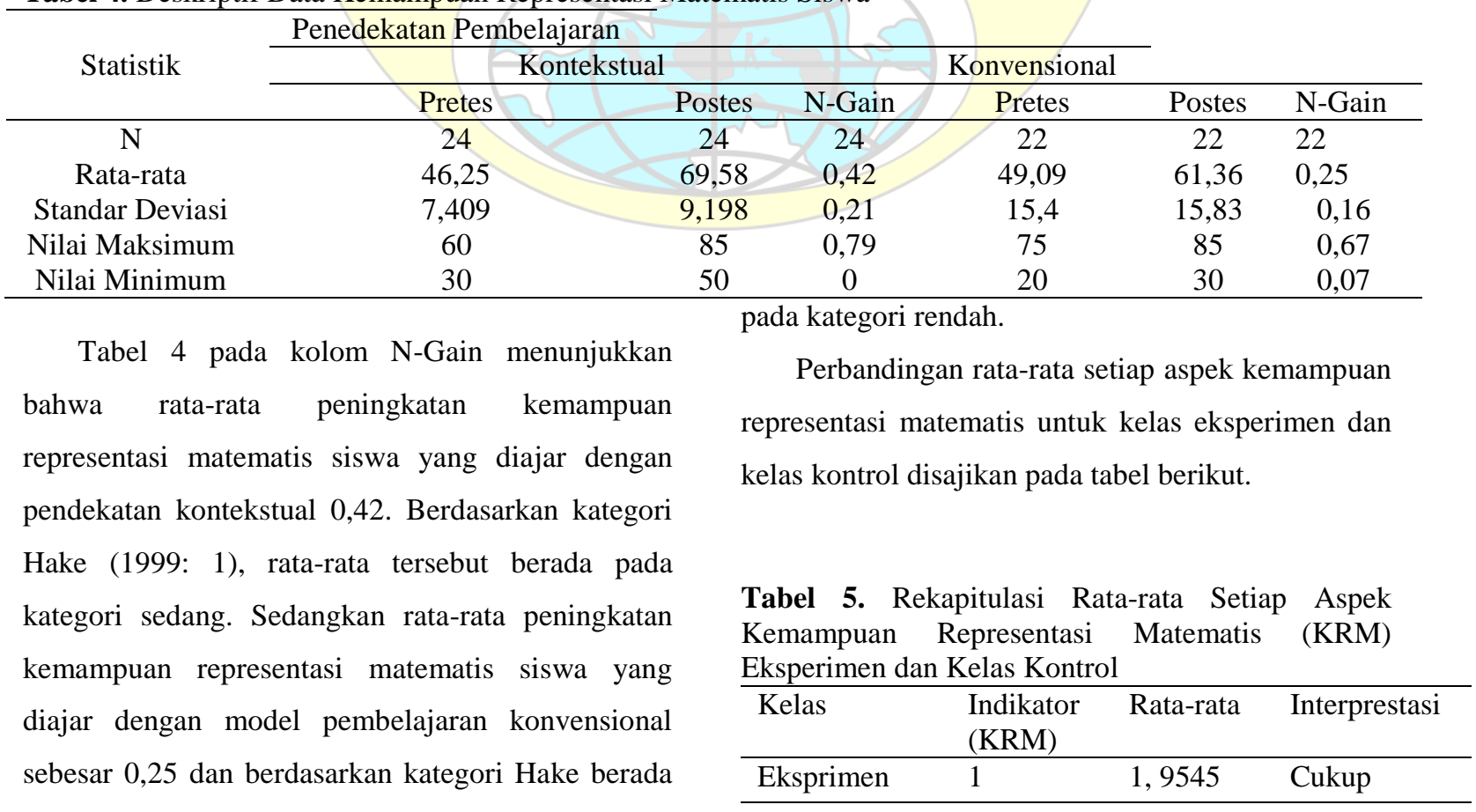


Ahmad Rustam ${ }^{1}$, Sardin $^{2}$ : Peningkatan Kemampuan Representasi Matematis melalui Pembelajaran Kontekstual Siswa Kelas VIII SMP

\begin{tabular}{lllll}
\hline & 2 & 2,3789 & Cukup & Setelah memenuhi uji prasyrat analisis statistik, \\
\multirow{3}{*}{ Kontrol } & 3 & 1,8182 & Cukup & dilanjutkan dengan analisis statistik inferensial uji \\
& 1 & 2,0454 & Cukup & beda satu sampel untuk melihat apakah hipotesis \\
& 2 & 2,2727 & Cukup & menerima atau menolak hipotesis secara signifikan. \\
& 3 & 1,6818 & Cukup & Berdasarkan hasil analisis nilai N-Gain untuk kelas
\end{tabular}

Selain itu, berdasarkan hasil analisis aktivitas siswa dalam proses pembelajaran ke dua pembelajaran, menunjukkan bahwa aktivitas siswa baik yang diajar dengan menggunakan pendekatan kontekstual maupun model pembelajaran konvensional mengalami peningkatan yang lebih baik berdasarkan indikator penilaian observasi. Namun demikian, pembelajaran dengan pendekatan kontekstual menunjukkan aktivitas siswa yang lebih baik dari siswa dengan pembelajaran konvensional.

b. Hasil Analisis Inferensial

Analisis ini bertujuan untuk menguji hipotesis yang diajukan, apakah hipotesis penelitian diajukan diterima atau ditolak. Sebelum melakukan analisis tersebut terlebih dahulu menguji asumsi prasyarat statistik yaitu apakah data berdistribusi normal dan homogenitas varians antar kelompok.

Uji normalitas data N-Gain setiap kelompok dalam penelitian ini menggunakan uji statistik Kolmogorov-Smirnov dengan bantuan aplikasi SPSS berikut hasil analisis pada tabel 6 .

Tabel 6. Hasil normalitas data

\begin{tabular}{ccc}
\multicolumn{2}{c}{ Tabel 6. Hasil normalitas data } & \\
\hline Kelas & Asymp. Sig. & Keterangan \\
& $(2$-tailed $)$ & \\
\hline Eksperimen & $0,200>(\alpha=$ & Normal \\
& $0,05)$ & \\
Kontrol & $0,064>(\alpha=$ & Normal \\
& $0,05)$ & \\
\hline
\end{tabular}

\section{Uji Homogenitas}

Sedangkan, Uji homogenitas varians menggunakan analisis Levene's Test dengan bantuan aplikasi SPSS diperoleh hasil yang disajikan pada tabel 7 .

Tabel 7. Hasil Analisis Homogenitas Data

\begin{tabular}{lll}
\hline $\begin{array}{l}\text { Levene } \\
\text { Statistic }\end{array}$ & Sig. & Keterangan \\
\hline 0,381 & 0,540 & Homogen \\
\hline
\end{tabular}

Uji Hipotesis 
kemampuan representasi matematis siswa dengan penerapan pendekatan kontekstual lebih tinggi dibanding model pembelajaran konvensional pada Siswa Kelas VIII SMP Negeri 2 Uluiwoi.

Berbagai upaya yang dilakukan untuk mengontrol kelompok perlakan, dimulai dari penentuan sampel, kemudian proses pembelajaran pada kelas eksperimen maupun kelas kontrol membahas materi pembelajaran yang sama, dan lainlain. Hal ini dilakukan untuk menjaga kondisi dari kedua kelas tetap homogen sehingga peningkatan yang terjadi benar akibat dari perlakuan dalam penelitian. Berdasarkan hasil pengamatan dengan menerapkan kedua model pembelajaran diperoleh informasi bahwa semua aspek yang diamati secara umum terlaksana dengan baik. Siswa antusias mengikuti pembelajaran, aktif berinteraksi, dan bersemangat untuk mengerjakan latihan soal yang diberikan oleh guru. Keaktifan siswa pada pembelajaran dengan pendekatan kontekstual menunjukkan perkembangan yang lebih baik dari pembelajaran konvensional.

Hasil uji statistik menunjukkan bahwa baik pendekatan kontektual maupun model pembelajaran konvensional efektif untuk diterapkan pada materi persamaan garis lurus siswa kelas VIII SMP Negeri 2 Uluiwoi. Namun demikian, setelah menganalisis lebih lanjut dengan membandingkan nilai rata-rata NGain kemampuan representasi matematis siswa menunjukkan bahwa kemampuan representasi matematis siswa yang diajar dengan pendekatan kontekstual lebih tinggi dibanding kemampuan representasi siswa yang diajar dengan menggunakan model pembelajaran konvensional. Hal ini berarti kemampuan representasi matematis siswa dengan penerapan pendekatan kontektual lebih efektif dibanding dengan penerapan model pembelajaran konvensional. Dengan kata lain, penerapan pendekatan kontekstual terbukti dapat meningkatkan kemampuan representasi matematis siswa. Hasil ini sejalan dengan penelitian (Rustam dan Adli, 2016: 7) menegaskan bahwa pembelajaran berbasis kontekstual dapat meningkatkan hasil belajar atau kemampuan siswa. Untuk itu, peningkatan kemampuan representasi matematis siswa secara optimal, maka menerapkan pembelajaran dengan menggunakan pendekatan kontekstual yang berbasis konteks sekitar.

\section{PENUTUP \\ Simpulan}

Dari hasil analisis dan pembahasan, maka disimpulan dalam penelitian ini bahwa:

1. Terdapat peningkatan rata-rata kemampuan representasi matematis siswa setelah mendapat pembelajaran kontekstual.

2. Terdapat peningkatan rata-rata kemampuan representasi matematis siswa setelah mendapat pembelajaran konvensional.

3. Peningkatan rata-rata kemampuan representasi matematis siswa dengan penerapan pendekatan kontekstual lebih tinggi dibanding model pembelajaran konvensional pada Siswa Kelas VIII SMP Negeri 2 Uluiwoi.

Saran

Berdasarkan kesimpulan tersebut disarankan agar, guru mata pelajaran matematika pendekatan kontekstual dapat digunakan sebagai alternatif dalam pembelajaran matematika untuk meningkatkan kemampuan representasi matematis siswa. Khusus materi persamaan garis lurus guru disarankan untuk menerapkan pembelajaran kontekstual, agar dapat terus meminimalisis persoalan rendahnya kemampuan representasi matematis.

\section{DAFTAR PUSTAKA}

Agung \& Suryani. (2012). Strategi Belajar Mengajar.

Yogyakarta: Ombak.

Djaali \& Muljono, P. (2008). Pengukuran dalam

Bidang Pendidikan. Jakarta: Grasindo. 
Ahmad Rustam ${ }^{1}$, Sardin $^{2}$ : Peningkatan Kemampuan Representasi Matematis melalui Pembelajaran Kontekstual Siswa Kelas VIII SMP

Dowdy, S. Wearden, S. \& Chilko, D. (2004). Statistics for Research: Third Edition. John Wiley \& Jersey

Hake, R.R. (1999). Analyzing Change/Gain Scores. Woodland Hills: Dept. Of Physics, Indiana University. [Online]. Tersedia: http://lists.asu.edu/cgibin/wa?A2=ind9903\&L=aera $-\mathrm{d} \& \mathrm{P}=\mathrm{R} 6855$.

Hamruni. (2011). Strategi Pembelajaran. Yogyakarta: Insani

Kurniasih \& Sani. (2015). Ragam Pengembangan Model Pembelajaran untuk Peningkatan Profesional Guru. Jakarta: Kata Pena.

Hasanah, A. (2004). Mangembangkan Kemampuan Pemahaman dan Penalaran Matematika Siswa SMP Melalui Pembelajaran Berbasis Masalah yang Menekankan Pada Representasi Matematik. Tesis pada SPS UPI. Bandung: Tidak diterbitkan.

Lie, A. (2008). Cooperative Learning: Mempraktikkan Cooperative Learning di Ruang-Ruang Kelas. Jakarta: Gramedia Widiasarana Indonesia.

Mudzakkir, H.S. (2006). Strategi Think- Talk- Write untuk Meningkatkan Kemampuan Representasi Matematik Beragam Siswa SMP. Tesis pada SPS UPI. Bandung: Tidak diterbitkan.

Mustangin, M. (2015). Representasi Konsep dan Peranannya dalam Pembelajaran Matematika di Sekolah. Jurnal Pendidikan Matematika, 1(1), 1521.

NCTM. (2000). Principles and Standards for School

Mathematics. Tersedia dalam www.standard.nctm.org (diakses pada tanggal 18 Desember 2016)

Saepuloh, A. R. (2013). Penerapan Model Pembelajaran Sinektik Untuk Meningkatkan

Kemampuan Representasi dan Komonikasi Metematis Siswa. Tesis pada SPs UPI. Bandung: Tidak diterbitkan.

Sudjana. (1989). Dasar-dasar Proses Belajar

Mengajar.Bandung: CV Sinar Baru.

Sundayana, R. (2014). Statistik Penelitian Pendidikan.
Alfabeta: Bandung.

Suryana. (2012). Guru Propesional Bandung: PT Refika Aditama.

Rustam, A. (2016). Dasar-dasar Statistik: Dilengkapi Analisis dengan Bantuan Excel dan SPSS 20. Kolaka: Putri Yolanda.

Rustam, A., \& Adli, M. (2016). Improving the Results of Math Learning Through Scramble Cooperative Model with the Approach of Contextual Teaching and Learning Model. Journal of Mathematics Education, 1(2 July), 7-13.

0

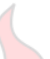

